\title{
THE IMPORTANCE OF SHEAR SLENDERNESS FOR DETERMINING PUNCHING RESISTANCE OF THE FOUNDATION FOOTINGS
}

\author{
J. Hanzel ${ }^{*}$, J. Halvonik ${ }^{* *}$, A. Bartók ${ }^{* * *}$, A. Vidakovič ${ }^{\dagger}$
}

\begin{abstract}
In the past, the concept of shear slenderness did not reach importance as at present. It is confirmed by the fact that for the second generation of Eurocode 2 the shear slenderness will play a significant role for an effective and safe assessment of the punching resistance of foundation slabs and footings.
\end{abstract}

Keywords: shear slenderness, punching resistance, footings, concept, calculation model

\section{Introduction}

Shear failure of the structure in case of the flat slabs and foundation footings can happen in two different ways. First is exceeding resistance of concrete compression diagonal, the second is exceeding punching shear resistance in the shear crack. In the past as well present, the formulae for the assessment of the punching shear resistance of foundation structures (slabs, footings) have been evaluated based on the tests of flat floor slabs.

\section{Basic parameters influencing punching shear resistance}

In the case of using any of theoretical models we have a lot of parameters influencing the assessment of the punching shear resistance of flat slabs and foundation footings. Each of the currently used models has a primarily determined the punching shear resistance using parameters like: strength of concrete $f_{\text {ck }}$, reinforcement ratio $\rho_{\mathrm{l}}$, effective depth $d$, but in some models is it the size of the aggregate $d_{\mathrm{g}}$.

The biggest difference between the first generation of valid Eurocode 2 EC2 (2004) model, the CSCT model described in Model Code 2010 [4] and the second generation Eurocode 2 EC2 (2017) model is determination of the critical control perimeter $a_{\mathrm{cr}}$ which is the distance measured from the face of a column where critical shear crack crosses main reinforcement. With lower shear slenderness, the critical shear cracks are steeper and critical control perimeters are closer to the face of a column. The MC 2010, as well as the upcoming EC2 (2017), have used basic control perimeter at distance $0.5 d$ from column face for flat slabs and as well as for footings. It is one of many changes affecting the assessment of punching shear resistance itself. In the EC2 (2004) is the basic control perimeter for the flat slabs set at $2 d$, which is twice of the effective depth $d$. In the case of foundation structures, we have to find the critical control perimeter in the range from $0.5 d$ to $2.0 d$. In this article, we will try to point out how greatly varies position of the critical control perimeter in depending of the shear slenderness.

\footnotetext{
Ing. Ján Hanzel: Slovak University of Technology, Facultyof Civil Engineering; Radlinského 11, 81005 Bratislava, SR, jan.hanzel@stuba.sk

** Prof. Ing. Jaroslav Halvonik, PhD.: Slovak University of Technology, Facultyof Civil Engineering; Radlinského 11, 81005 Bratislava, SR, Jaroslav.halvonik@stuba.sk

*** Ing. Andrej Bartók, PhD.: Slovak University of Technology, Facultyof Civil Engineering; Radlinského 11, 81005 Bratislava, SR, andrej.bartok@stuba.sk

$\dagger$ Ing. AleksandarVidakovič: Slovak University of Technology, Facultyof Civil Engineering; Radlinského 11, 81005 Bratislava, SR, aleksandar.vidakovic@stuba.s
} 


\section{An influence of the shear slenderness on the punching capacity}

One of the biggest changes that are currently being prepared and they influence the assessment of the punching shear resistance is the elimination of the requirement to find an exact location of the critical control perimeter where shear crack crosses main reinforcement in the foundation structures laying within the range from $0.5 d$ to $2.0 d$. Instead, each assessment will be considered at a distance of $0.5 d$. Introducing this parameter, there will be great differences in the determination of shear resistance, since the place of the critical shear crack will always be primarily dependent on the shear slenderness $a_{\mathrm{i}} / d_{\mathrm{i}}$. Any of parameters like: effective depth $d_{\mathrm{i}}$, strength of concrete $f_{\text {ck }}$, reinforcement ratio $\rho_{\mathrm{l}}$, and as well as the load or soil pressure, do not affect the determination of the exact location of shear crack crosses main reinforcement, i.e. the location of the critical control perimeter $a_{\text {crit }}[\mathrm{m}]$. The term shear slenderness $a_{\mathrm{i}} / d_{\mathrm{i}}$ is applies for flat slabs and foundation structures. The shear span $a_{\mathrm{i}}$ represents distance measured from the face of the support to the place where radial bending moments are equal to zero. Because zero bending moments are located at the ends of the footings the shear slenderness is defined as ratio of the footing overhang and effective depth. The value of $a_{\text {crit }}$ is distance measured from column face to place where equilibrium of vertical shear forces, or principal stresses due to load with shear resistance is reached. The first mode of failure (crushing of concrete struts) develops mostly in the footings with slender column (with short length of column periphery) and high axial force. In Fig.1 is shown changing position of $a_{\text {crit }}$ from $0.5 d_{\mathrm{i}}$ to $1.36 d_{\mathrm{i}}$. Scheme clearly declares that footings with the same effective depth $d$ may have different position of the $a_{\mathrm{cr}}$ for different shear slenderness.

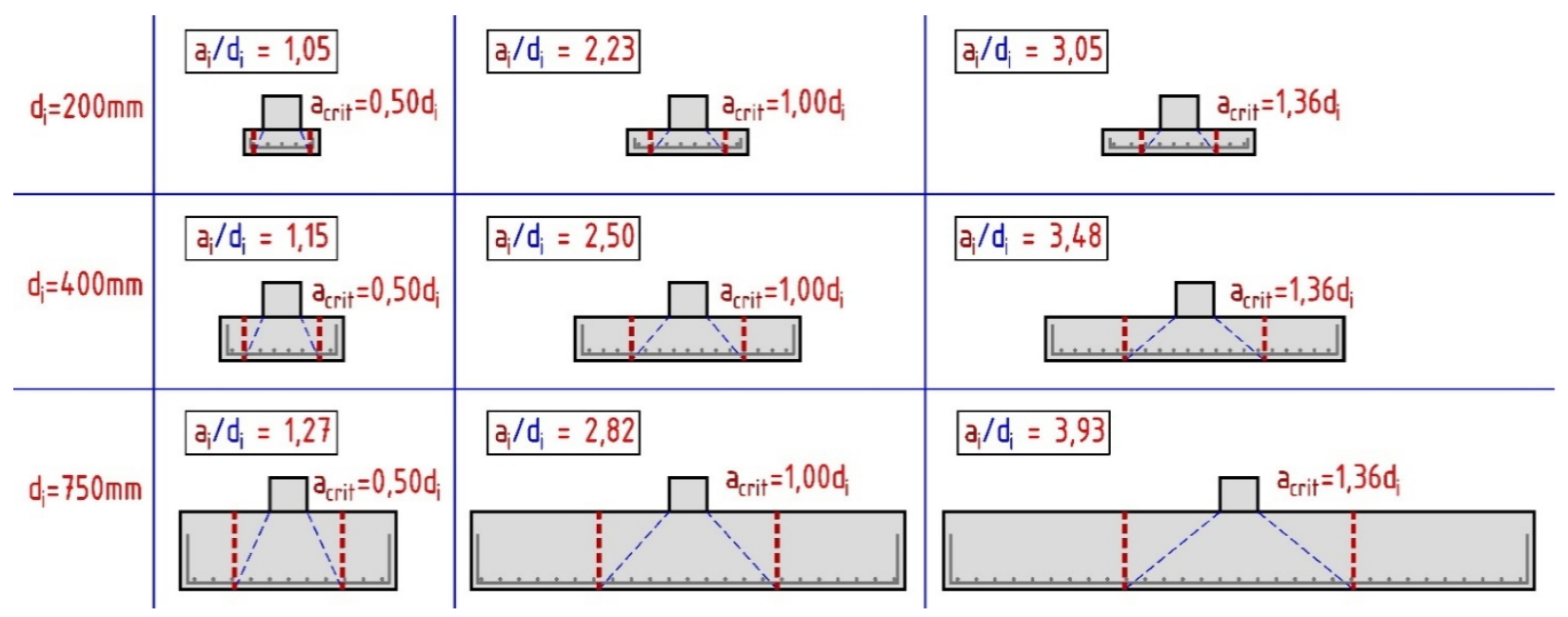

Fig. 1: Impact of the changing shear slenderness $a_{i} / d_{i}$ on the position $a_{c r i}$ of the critical control parameter

\section{Effect of the shear slenderness on model results}

For the current valid first generation of EC2 (2004) is favourable effect of concrete compressive diagonal $2 d_{\mathrm{i}} / a_{\mathrm{i} . c r i t}$, which is part of the $v_{\mathrm{Rd}, \mathrm{c}}$ calculation (2), and has significant part of the for overall punching shear resistance $v_{\mathrm{Rd}, \mathrm{c}}[\mathrm{MPa}]$.

$$
\begin{gathered}
V_{\mathrm{Rd}, \mathrm{c}}=v_{\mathrm{Rd}, \mathrm{c}} u_{\text {ucrit }} d \quad[\mathrm{MN}] \\
v_{\mathrm{Rd}, \mathrm{c}}=\frac{0.18}{g_{\mathrm{C}}} k_{h}\left(100 r_{1} f_{\mathrm{ck}}\right)^{\frac{1}{3}} \frac{2 d}{a_{c r i t}} \quad[\mathrm{MPa}]
\end{gathered}
$$

The substantial impact of concrete diagonal can be interpreted in the case of foundation footings with a critical shear crack $a_{\text {crit }}$ at a distance of $0.5 d_{\mathrm{i}}$ from the face of the column. As we see in Fig.1. In this case the positive effect of the concrete diagonal $2 d_{\mathrm{i}} / a_{\mathrm{i} . \text { crit }}$ which increases the shear resistance of $\mathrm{v}_{\mathrm{Rd}, \mathrm{c}}[\mathrm{MPa}]$ is more than 4 times higher. If the critical shear crack $a_{\mathrm{i} . \text { crit }}$ is located at a distance of $1.0 d_{\mathrm{i}}$ from the column face, the shear resistance $\mathrm{v}_{\mathrm{Rd}, \mathrm{c}}[\mathrm{MPa}]$ is increased 2 times. In the case of the last foundation footing, see Fig. 1, it is 1.5 times. For MC 2010 model, which always serves as a background in the preparation of a new generation of Eurocode 2, the calculation of $v_{\mathrm{Rd}, \mathrm{c}}$ according to (3) is dependent on concrete strength and size of rotation of flat slab or foundation structures. This model, since rotation of flat slab directly takes account of shear slenderness $a_{\mathrm{i}} / d_{\mathrm{i}}$, is more physical. The place of the shear failure is precisely 
designed to $0.5 d$ from the face of the column. The size of the control perimeter $b_{0}$ will depend only on the effective depth $d$ without the impact of the shear slenderness as is in the first generation of EC 2 (2004), when the location of failure for foundation footings have to be found in the range from $0.5 d$ to $2.0 d$.

$$
\begin{gathered}
V_{\mathrm{Rd}, \mathrm{c}}=b_{0} d_{v} v_{\mathrm{Rd}, \mathrm{c}} \\
v_{\mathrm{Rd}, \mathrm{c}}=k_{y} \frac{\sqrt{f_{\mathrm{ck}}}}{g_{\mathrm{C}}}
\end{gathered}
$$

$k_{\psi}$ is coefficient taking into account an influence of critical shear crack width on punching resistance, which depends mainly on slab rotation $\psi[-]$. The formula takes also into account an influence of aggregate size $d_{\mathrm{g}}[\mathrm{mm}]$ and size effect through $d[\mathrm{~mm}]$ on punching resistance.

The EC2 (2017) model is part of second generation of Eurocode 2. The model is based on CSCT theory and is introduced in closed form in order to simplify the assessment of the punching capacity for designers. Verification should be carried out at control perimeter wit distance $0.5 d$ from the column periphery.

$$
\begin{gathered}
V_{\mathrm{Rd}, \mathrm{c}}=b_{0} d_{v} t_{\mathrm{Rd}, \mathrm{c}}[\mathrm{MN}] \\
t_{\mathrm{Rd}, \mathrm{c}}=\frac{k_{b}}{g_{\mathrm{C}}}\left(100 r_{1} f_{\mathrm{ck}} \frac{d_{d g}}{a_{p}}\right)^{\frac{1}{3}} \leq \frac{0,6}{g_{\mathrm{C}}} \sqrt{f_{c k}} \quad[\mathrm{MPa}] \\
a_{\mathrm{p}}=\sqrt{a_{p, x} a_{p, y}} \geq 2,5 d \quad[\mathrm{~mm}]
\end{gathered}
$$

Where $a_{\mathrm{p}, \mathrm{x}}$ and $a_{\mathrm{p}, \mathrm{y}}$ are shear slenderness in two orthogonal directions

\section{An experimental analysis of shear slenderness influence on models for assessment of punching shear resistance}

Three basic sets with different shear slenderness $a_{\mathrm{i}} / d_{\mathrm{i}}$ were selected from the database of 50 experiments on the footings. The goal of the analysis was estimation of the model safety for different shear slenderness and point out importance of the new tests on footings with slenderness higher than 2.5 , see Fig. 2. As can be seen in Table 2 only two footings have had slenderness higher than 2.5 with maximum 2.9. Model EC2 (2017), which is introduced in second generation of Eurocode 2, minimises shear slenderness by 2.5. For lower slenderness value of 2.5 shall be used.

Tab. 1: Statistical evaluation of the model safety for three different ranges of shear slenderness

\begin{tabular}{cccccccc}
\hline Set & Model & $a_{\mathrm{i}} / d_{\mathrm{i}}$ & $\begin{array}{c}C_{\mathrm{Rk}, \mathrm{c}} \\
{[\mathrm{MPa}]}\end{array}$ & Ratio & $\begin{array}{c}\text { Level of } \\
\text { Approx. }\end{array}$ & $\begin{array}{c}\text { Number of } \\
\text { specimens }\end{array}$ & $\begin{array}{c}\text { Average value of } \\
\text { the safety factor }\end{array}$ \\
\hline $\mathrm{P}(1.1)$ & $\mathrm{EC} 2(2004)$ & $1.5-2.0$ & 0.18 & $2 d / a$ & - & 10 & 0.821 \\
\hline $\mathrm{P}(1.2)$ & $\mathrm{EC} 2(2004)$ & $2.0-2.5$ & 0.18 & $2 d / a$ & - & 10 & 0.799 \\
\hline $\mathrm{P}(1.3)$ & $\mathrm{EC} 2(2004)$ & $2.5-2.9$ & 0.18 & $2 d / a$ & - & 2 & 0.902 \\
\hline $\mathrm{P}(2.1)$ & MC 2010 & $1.5-2.0$ & - & - & III. & 10 & 1.049 \\
\hline $\mathrm{P}(2.2)$ & MC 2010 & $2.0-2.5$ & - & - & III. & 10 & 0.973 \\
\hline $\mathrm{P}(2.3)$ & MC 2010 & $2.5-2.9$ & - & - & III. & 2 & 1.307 \\
\hline $\mathrm{P}(3.1)$ & $\mathrm{EC} 2(2017)$ & $1.5-2.0$ & - & - & - & 10 & 0.938 \\
\hline $\mathrm{P}(3.2)$ & $\mathrm{EC} 2(2017)$ & $2.0-2.5$ & - & - & - & 10 & 0.868 \\
\hline $\mathrm{P}(3.3)$ & $\mathrm{EC} 2(2017)$ & $2.5-2.9$ & - & - & - & 2 & 1.094 \\
\hline $\mathrm{P}(4.1)$ & $\mathrm{EC} 2(2004)^{1)}$ & $1.5-2.0$ & 0.18 & $1.50^{1)} d / a$ & - & 10 & 1.094 \\
\hline $\mathrm{P}(4.2)$ & EC2 $(2004)^{1)}$ & $2.0-2.5$ & 0.18 & $1.50^{1)} d / a$ & - & 10 & 1.065 \\
\hline $\mathrm{P}(4.3)$ & $\mathrm{EC} 2(2004)^{1)}$ & $2.5-2.9$ & 0.18 & $1.50^{1)} d / a$ & - & 2 & 1.202 \\
\hline 1$)$ & Proposed modification of the EC2 (2004) model in order to reach higher safety &
\end{tabular}


Average values of ratio $V_{\text {Test }} / V_{\mathrm{Rd}, \mathrm{c}}$ (punching capacity of the test/assessed punching capacity) are lowest for sets $\mathrm{P}(1.1)$ to $\mathrm{P}(1.3)$ and they are below $90 \%$ in case of EC2 (2004). The analysis shows that favourable influence of the concrete struts $2 d / a$ is slightly overestimated and pushes assessed punching capacities to the unsafe zone. Modest modification of the concrete strut effect to $1.5 \mathrm{~d} / \mathrm{a}$ increases an average value of the ratio $V_{\text {Test }} / V_{\mathrm{Rd}, \mathrm{c}}$ over one, which means on the safe and still economic side. In case of MC2010 model, see set $\mathrm{P}(2.1)$ - $\mathrm{P}(2.3)$, we can conclude that the model is very well calibrated for any shear slenderness from interval 1.5 to 2.9 and provides proper results. In case of EC2 (2017) model the average value of the ratio $V_{\text {Test }} / V_{\mathrm{Rd}, \mathrm{c}}$ is slightly below one which means the model is properly calibrated

In case of the statistical evaluation of EC2 (2017) model safety with all 50 tests, sets $\mathrm{P}(5.1)$ - $\mathrm{P}(5.3)$, the mean value of the ratio $V_{\text {Test }} / V_{\mathrm{Rd}, \mathrm{c}}$ is 0.895 , COV 0.133 and $5 \%$ fractile $P_{\mathrm{k}, 0.05}=0.688$. This indicates insufficient model safety. The model safety can be increased by modification of enhancement factor $k_{\mathrm{b}}$ where value of 8 is replaced by 6 or by 4 , see formulae (9) -(11). The value of 4 will increase model safety to value which is close to one.

$$
k_{b}=\sqrt{8 \mu_{p} \frac{d}{b_{0}}} \leq 3[-] \quad(9) ; \quad k_{b}=\sqrt{6 \mu_{p} \frac{d}{b_{0}}} \leq 3[-] \quad(10) ; \quad k_{b}=\sqrt{4 \mu_{p} \frac{d}{b_{0}}} \leq 3[-]
$$

Tab. 2: Statistical evaluation of 50 different shear slenderness according to new proposal of Euro Code

\begin{tabular}{cccccccc}
\hline Set & Model & $a_{\mathrm{i}} / d_{\mathrm{i}}$ & $k_{\mathrm{b}}$ & $\begin{array}{c}\text { Number of } \\
\text { specimens }\end{array}$ & $\begin{array}{c}\text { Average } \\
\text { value }\end{array}$ & COV & $P_{\mathrm{k}, 0.05}$ \\
\hline $\mathrm{P}(5.1)$ & $\mathrm{EC} 2(2017)$ & $0.5-2.9$ & $k_{\mathrm{b}}(9)$ & 50 & 0.895 & 0.1334 & 0.688 \\
\hline $\mathrm{P}(5.2)$ & $\mathrm{EC} 2(2017)$ & $0.5-2.9$ & $k_{\mathrm{b}}(10)$ & 50 & 1.011 & 0.1259 & 0.791 \\
\hline $\mathrm{P}(5.3)$ & $\mathrm{EC} 2(2017)$ & $0.5-2.9$ & $k_{\mathrm{b}}(11)$ & 50 & 1.231 & 0.1259 & 0.963 \\
\hline
\end{tabular}

\section{Conclusions}

The analysis confirmed insufficient safety of the current EC2 (2004) model for the assessment of punching capacity of the footings without transverse reinforcement. Modification of the parameter which takes into account an effect of concrete struts has significantly improved safety. Probably the best results provide MC2010 model for LoAIII. No changes are proposed. The model EC2 (2017) has very good accuracy because COV is pretty low, but the lower mean value of ratio $V_{\text {Test }} / V_{\mathrm{Rd}, \mathrm{c}}$ indicates requirements for the model adjustment. The best way is modification of the factor $k_{\mathrm{b}}$. Overview of the experiments shows that only small number of footings with shear slenderness over 2.5 where tested, no one with slenderness over 3 . Therefore, an experimental campaign on footings with higher shear slenderness was prepared in laboratory of Slovak university of technology in Bratislava.

\section{Acknowledgement}

This work was supported by the Slovak Research and Development Agency under the contract VEGA No. $1 / 0810 / 16$.

\section{References}

Halvoník, J., Hanzel, J. and Majtánová, L. (2016a) Punching resistance of spread footings, in: Interdisciplinarity in theory and practice [electronic source]. No. 11, online, s. 64-70. ISSN 2344-2409.

Halvoník, J., Hanzel, J. and Majtánová, L. (2016b) Reliability of the models for assessment of punching resistance of footings, in: Performance-based approaches for concrete structures [electronic source] : proceedings. Cape Town, South Africa, 21-23 November 2016. 1. pub. Lausanne : Fédérationinternationaledubéton (fib), 2016, CD-ROM, [7] s. ISBN 978-2-88394-121-2.

Labudkova, J. and Cajka, R. (2014) Comparison of Measured Deformation of the Plate in Interaction with the Subsoil and the Results of 3D Numerical Model. Advanced Materials Research Vol.1020 (2014) pp 204-209, Trans Tech Publications, Switzerland, doi: 10.4028/www.scientific.net/AMR.1020.204.

Muttoni, A., and Ruiz, F.M., (2012) The levels of approximation approach in MC 2010: applications to punching shear provisions, Structural Concrete, Germany, Vol. 13, No. 1, 2012, pp. 32-41

Muttoni, A., and Ruiz, F. (2017) Provisions for shear and punching shear, 8th draft, Presentation from CEN/TC250/SC2/WG1/TG4 meeting in Amsterdam, 24. March 2017 